\title{
Oximetry with the NMR signals of hemoglobin Val E11 and Tyr C7
}

\author{
Hongtao Xie · Ulrike Kreutzer · Thomas Jue
}

Accepted: 29 June 2009/Published online: 21 July 2009

(C) The Author(s) 2009. This article is published with open access at Springerlink.com

\begin{abstract}
The NMR visibility of the signals from erythrocyte hemoglobin $(\mathrm{Hb})$ presents an opportunity to assess the vascular $\mathrm{PO}_{2}$ (partial pressure of oxygen) in vivo to gather insight into the regulation of $\mathrm{O}_{2}$ transport, especially in contracting muscle tissue. Some concerns, however, have arisen about the validity of using the Val E11 signal as an indicator of $P \mathrm{O}_{2}$, since its intensity depends on tertiary structural changes, in contrast to the quaternary structure changes associated with relaxed $(\mathrm{R})$ and tense $(\mathrm{T})$ transition during $\mathrm{O}_{2}$ binding. We have examined the Val E11 and Tyr C7 signal intensity as a function of $\mathrm{Hb}$ saturation by developing an oximetry system, which permits the comparative analysis of the NMR and spectrophotometric measurements. The spectrophotometric assay defines the $\mathrm{Hb}$ saturation level at a given $\mathrm{PO}_{2}$ and yields standard oxygen-binding curves. Under defined $\mathrm{PO}_{2}$ and $\mathrm{Hb}$ saturation values, the NMR measurements have determined that the Val E11 signal, as well as the Tyr C7 signal, tracks closely $\mathrm{Hb}$ saturation and can therefore serve as a vascular oxygen biomarker.
\end{abstract}

Keywords Muscle - Oxygen transport - Oxygen · Myoglobin · Bioenergetics

\section{Introduction}

The detection of the ${ }^{1} \mathrm{H}$ NMR Mb (myoglobin) signals in vivo has presented an approach to measure intracellular oxygenation under different physiological conditions

H. Xie · U. Kreutzer · T. Jue $(\bowtie)$

Department of Biochemistry and Molecular Medicine,

University of California Davis, Davis, CA 95616-8635, USA

e-mail: TJue@ucdavis.edu
(Chung et al. 2005; Ponganis et al. 2008; Kreutzer et al. 1992). Such measurements provide insight into the role of $\mathrm{O}_{2}$ in regulating bioenergetics, especially during muscle contraction. Because these signals also appear in $\mathrm{Hb}$, an opportunity exists to assess both the vascular and intracellular $\mathrm{PO}_{2}$ to clarify the regulatory interaction between metabolism and oxygen transport (Kreutzer et al. 1993; Fetler et al. 1995).

In particular, the NMR methodology depends on the protein structural transition during oxygenation and deoxygenation, which alters the intensity of the proximal histidyl $\mathrm{N}_{\delta} \mathrm{H}$ and $\gamma \mathrm{CH}_{3}$ Val E11 signals. Given the normalized signal intensity and the in vitro $\mathrm{O}_{2}$ association constant, experiments can determine the intracellular $\mathrm{PO}_{2}$ (Jue 1994; Kreutzer et al. 1992). For the proximal histidyl $\mathrm{N}_{\delta} \mathrm{H}$, its signal intensity reaches a maximum in the fully deoxygenated state. Using the Val E11 avoids the anoxia condition, because the signal reaches a maximum intensity in the oxygenated state. Moreover, using the ratio of the proximal histidyl $\mathrm{N}_{\delta} \mathrm{H}$ and $\gamma \mathrm{CH}_{3} \mathrm{Val}$ E11 signals helps discriminate signal intensity changes arising from oxygenation instead of blood volume (Kreutzer et al. 1992).

However, unlike monomeric $\mathrm{Mb}$, the Val E11 signal intensity of tetrameric $\mathrm{Hb}$ reflects both tertiary and quaternary structural changes. Some researchers have raised concerns that the Val E11 signal intensity might not report accurately the state of $\mathrm{Hb}$ saturation (Fetler et al. 1995). The concern predicates on the Perutz's interpretation of the Monod, Wyman and Changeux (MWC) two-state model of $\mathrm{Hb}$ oxygen binding. Only the movement of the proximal histidine links directly to the hydrogen bonding at the subunit interface as the quaternary structure shifts between the relaxed (R) to tense (T) state (Monod et al. 1965; Weissbluth 1974; Perutz 1989; Perutz et al. 1998; Bruno et al. 2001). The model does not associate specifically a $T$ 
to $\mathrm{R}$ transition with any structural perturbation affecting the Val E11.

We have hypothesized that the $\mathrm{R}$ to $\mathrm{T}$ quaternary structural change affects similarly the signals of $\gamma \mathrm{CH}_{3} \mathrm{Val}$ E11 and Tyr C7, a quaternary state marker at the subunit interface. These signals will reflect accurately the state of $\mathrm{Hb}$ oxygenation. We have conducted a comparative spectrophotometric and NMR study of $\mathrm{Hb}$ with and without inositol hexaphosphate (IHP), a stable analog of the endogenous BPG (2, 3 bisphophoglycerate) allosteric effector found in erythrocytes, and at different values of $\mathrm{pH}$ and $\mathrm{PO}_{2}$. Indeed, the spectrophotometric and NMR assays yield oxygen-binding curves in excellent agreement with previous literature reports (Chang et al. 2002; Gong et al. 2006; Lukin and Ho 2004; Asakura and Lau 1978; Benesch et al. 1967; Rossi-Fanelli et al. 1961). As a consequence, the results confirm that ${ }^{1} \mathrm{H}$ NMR signal of either the $\gamma \mathrm{CH}_{3} \mathrm{Val}$ E11 or Tyr $\mathrm{C} 7$ responds sensitively to the structural changes in the $\mathrm{R}$ to $\mathrm{T}$ transition, reports accurately the $\mathrm{Hb}$ oxygenation state, and can serve as a vascular oxygen biomarker.

\section{Materials and methods}

\section{In vitro experiment preparation}

Hemoglobin was prepared as previously reported (Kreutzer et al. 1993; Wang et al. 1997). Fresh outdated red blood cells were centrifuged for $15 \mathrm{~min}$ at $600 \times g$ and washed three times with $1 \% \mathrm{NaCl}$ solution. For $\mathrm{Hb}$ solution experiments, the erythrocytes were lysed with three volumes of distilled $\mathrm{H}_{2} \mathrm{O}$ and contaminant proteins precipitated with $20 \%$ of saturated ammonium sulfate. The lysate was centrifuged for $30 \mathrm{~min}$ at $10,000 \times g$ and then dialyzed against $100 \mathrm{mM}$ potassium phosphate buffer ( $\mathrm{pH}$ 7.4). Bubbling $\mathrm{CO}$ then converted the $\mathrm{HbO}_{2}$ to $\mathrm{HbCO}$, which was stored at $4^{\circ} \mathrm{C}$. Converting $\mathrm{HbCO}$ to $\mathrm{HbO}_{2}$ required a bright light to photodissociate $\mathrm{CO}$ from cold $\mathrm{HbCO}$ under a stream of $\mathrm{O}_{2}$.

All $\mathrm{Hb}$ samples used for optical and NMR studies were 0.025 or $0.125 \mathrm{mM}$ in $\mathrm{Hb}$ tetramer in $100 \mathrm{mM}$ phosphate buffer at $\mathrm{pH}$ 7.0. Concentration of $\mathrm{HbO}_{2}$ and deoxy $\mathrm{Hb}$ on a heme basis was determined by spectrophotometric measurement (UVIKON 941, Kontron Instruments) of the $\mathrm{Hb}$ bands. Extinction coefficients of $\varepsilon_{541}=13.8 \mathrm{mM}^{-1} \mathrm{~cm}^{-1}$, $\varepsilon_{577}=14.6 \mathrm{mM}^{-1} \mathrm{~cm}^{-1}$ and $\varepsilon_{555}=12.5 \mathrm{mM}^{-1} \mathrm{~cm}^{-1}$ (Antonini and Brunori 1971) were used to calculate $\mathrm{Hb}$ concentration. Visible spectra of the $\mathrm{Hb}$ samples were taken before and after the NMR experiment to measure $\mathrm{HbO}_{2}$ concentration and to detect the presence of any metHb. Only data from samples with no detectable metHb were used in the analysis.
Oxygen equilibration system

Appropriate $\mathrm{HbO}_{2}$ saturations were obtained by equilibrating Hb solution in a home-built system shown in Fig. 1. The closed loop system consists of a peristaltic pump (Cole-Parmer, Cartridge pump model: 07519-15), tubing (Pharmed, Lot No.: 201923), gas-mixing chamber with $\mathrm{O}_{2}$ permeable silastic tubing (Dow Corning, Cat.No.: 508-006), polarographic oxygen monitor (Cameron Instruments, OM2000), gas mixer (Cameron Instruments, GF-4/MP) and humidifier. The pump circulated about $40 \mathrm{ml}$ of humidified $\mathrm{HbO}_{2}$ through the silastic tubing wrapped around a plastic rack, which maximized the surface area for $\mathrm{O}_{2}$ exchange, and then through an NMR tube and/or cuvette. At a flow rate of $40 \mathrm{ml} / \mathrm{min}$, the entire solution volume passed through the system within $1 \mathrm{~min}$. The gas mixer introduced a precise ratio of $\mathrm{O}_{2}$ or $\mathrm{N}_{2}$ into the gas-mixing chamber to achieve different $P \mathrm{O}_{2}$. An oxygen meter equipped with a Clark-type oxygen electrode determined the $\mathrm{PO}_{2}$ of the $\mathrm{HbO}_{2}$ solution. A spectrophotometer then measured the $\mathrm{HbO}_{2}$ signals from 450 to $650 \mathrm{~nm}$ with $1 \mathrm{~nm}$ resolution. The NMR spectrometer recorded the ${ }^{1} \mathrm{H}$ NMR signals of $\mathrm{Hb}$ in the presence or absence of IHP and at identical $P_{2}$ values. A $5 \mu \mathrm{m}$

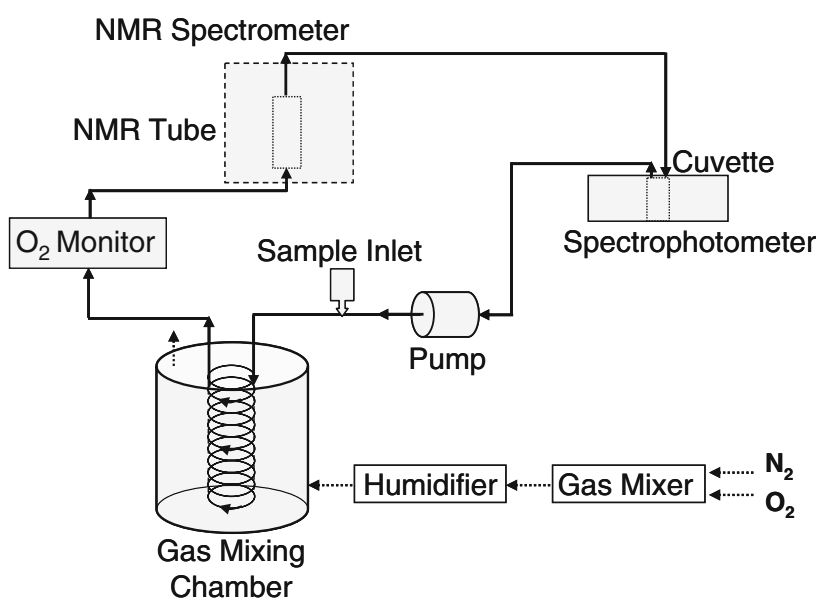

Fig. 1 The oxygen equilibration system that permits coordinated spectrophotometric and NMR measurements: The system components comprise a peristaltic pump, gas-mixing chamber with $\mathrm{O}_{2}$ permeable tubing, a gas mixer to create different mixtures of $\mathrm{O}_{2}$ and $\mathrm{N}_{2}$, an $\mathrm{O}_{2}$ monitor, spectrophotometer or NMR spectrometer, and connecting tubings to form a closed loop. $\mathrm{Hb}$ injected into inlet port circulates into the gas-mixing chamber, where it equilibrates with the $\mathrm{O}_{2} / \mathrm{N}_{2}$ mixture defined by the gas mixer. The equilibrated $\mathrm{Hb}$ solution loops through either a spectrophotometer switch or an NMR spectrometer switch. For spectrophotometric assay, the $\mathrm{Hb}$ solution would circulate through a cuvette as the spectrophotometer records the optical spectra. For the NMR assay, the $\mathrm{Hb}$ solution would enter the NMR tube from the bottom and recirculate into the gas-mixing chamber. The NMR spectrometer would record the ${ }^{1} \mathrm{H}$ NMR spectra. A typical experiment utilizes $40 \mathrm{ml}$ of $\mathrm{Hb}$, which circulates at $40 \mathrm{ml} / \mathrm{min}$ 
Millipore (Millipore, Molsheim) filter removed any particulate material.

\section{Oxygen-binding curve}

A spectrophotometer determined the $\mathrm{O}_{2}$-binding curves of $0.025 \mathrm{mM} \mathrm{Hb}$ in $100 \mathrm{mM}$ inorganic phosphate $(\mathrm{Pi})$ buffer as a function of $\mathrm{pH}(6.6-7.5)$ with and without IHP at $25^{\circ} \mathrm{C}$. Sodium inositol hexaphosphate (IHP) was added in IHP:Hb (tetramer) molar ratio of 5:1. The addition of $0.1 \mathrm{~N} \mathrm{HCl}$ or $0.1 \mathrm{~N} \mathrm{NaOH}$ adjusted the $\mathrm{pH}$ of $\mathrm{HbO}_{2}$ as verified by a Corning (Model 240) pH meter. The spectrophotometer recorded the $\mathrm{Hb}$ saturation after a cycle of deoxygenation and reoxygenation at $0,1,1.5,2,3,5,7,10$ and $21 \% \mathrm{O}_{2}$, corresponding to $\mathrm{PO}_{2}$ values between 0 and $154 \mathrm{mmHg}$. Each $\mathrm{PO}_{2}$ step required about $7 \mathrm{~min}$ to equilibrate with the different $P_{2}$. Two spectra were recorded for each $P_{2}$ step. A complete experiment usually required about $90 \mathrm{~min}$. After the experiment, sodium dithionite was added to create the totally desaturated $\mathrm{Hb}$ state and the associated reference spectrum.

$\mathrm{HbO}_{2}$ fractional saturation

The fractional $\mathrm{HbO}_{2}$ saturation $Y=\frac{\mathrm{HbO}_{2}}{\mathrm{HbO}_{2}+\mathrm{Hb}}$ was determined from the absorbance change in the $\mathrm{HbO}_{2} \beta(541 \mathrm{~nm})$ and $\alpha(577 \mathrm{~nm})$ and the deoxy $\mathrm{Hb}(555 \mathrm{~nm})$ bands. The analysis of the curve fit of $Y$ versus $\mathrm{PO}_{2}$ with either the equation

$Y=\frac{P \mathrm{O}_{2}^{n_{\text {Hill }}}}{P \mathrm{O}_{2}^{n_{\text {Hill }}}+P_{50}^{n_{\text {Hill }}}}$

or with the Hill equation

$\log \frac{Y}{1-Y}=n_{\text {Hill }} \log P \mathrm{O}_{2}$

led to the determination of the $P_{50}$ (partial $\mathrm{O}_{2}$ pressure at $50 \%$ saturation) and the Hill coefficient, $n_{\text {Hill. }}$.

\section{NMR}

${ }^{1} \mathrm{H}$ NMR experiments were performed on an Avance 400$\mathrm{MHz}$ Bruker NMR spectrometer using a $20-\mathrm{mm}$ microimaging probe (R31/1 20-40/MI-400-R014). A specially designed sample NMR tube was mounted inside the probe with the entrance port at the bottom and the exit port at the top. After equilibrating the $\mathrm{Hb}$ to a specified $\mathrm{PO}_{2}$, the $\mathrm{Hb}$ flowed into the probe from the bottom of the magnet and exited from the top to form a closed loop system. Typical experiment used $0.125 \mathrm{mM} \mathrm{HbA}$ in $100 \mathrm{mM}$ Pi buffer at $25^{\circ} \mathrm{C}$. Chemical shifts were referenced to the water proton signal at $4.75 \mathrm{ppm} 25^{\circ} \mathrm{C}$, calibrated against 2-dimethyl-2silapentane-5-sulfonate (DSS).
The ${ }^{1} \mathrm{H}$ NMR signals were normalized to $\mathrm{Hb}$ signals under fully oxygenated or deoxygenated conditions. After the NMR experiment, the relative signal intensities (integrated peak areas) of ${ }^{1} \mathrm{H}$ NMR peaks at each oxygenation state were determined by normalizing the signal intensity to its full oxygenated and deoxygenated condition.

A 1-5-10-10-5-1 pulse sequence suppressed the water signal and produced a sufficient uniform excitation profile in the region of interest (Hore 1983). A typical $\mathrm{HbO}_{2}$ spectrum used $8 \mathrm{kHz}$ spectral width, $1 \mathrm{~K}$ data points and 512 scans. The $90^{\circ}$ pulse calibrated against the water proton signal was $50 \mu \mathrm{s}$. Zero-filling improved the spectral resolution. Apodizing the free induction decay (FID) with an exponential or an exponential-Gaussian window function improved the spectra. A spline fit then smoothed the baseline.

Statistical analysis

Statistical analysis used the Sigma Plot/Sigma Stat program (Systat Software, Inc., Point Richmond, CA) and expressed the values as mean value \pm standard deviation (SD). Statistical significance was determined by two-tailed unequal variance Student's $t$ test with no statistical difference indicated by $P>0.05$.

\section{Results}

Figure 1 shows the schematic representation of the closed loop system, which contains $\mathrm{Hb}$ circulating through a gasmixing chamber, $\mathrm{O}_{2}$ monitor and an NMR tube or a spectrophotometer cuvette. A gas mixer supplies a specific mixture of $\mathrm{N}_{2}$ and $\mathrm{O}_{2}$ to the chamber, which allows the $\mathrm{Hb}$ solution to equilibrate at a defined $P_{2}$. A spectrophotometer monitors the changes in the $\mathrm{Hb}$ bands to ensure full equilibration. After the $\mathrm{Hb}$ has equilibrated, these bands lead to the determination of the $\mathrm{Hb}$ saturation. A plot of the $\mathrm{Hb}$ saturation as a function of $\mathrm{PO}_{2}$ yields the oxygen-binding curve. With the identical protocol, NMR can correlate the changes in the Val E11 and Tyr C7 signals, a tertiary and quaternary protein structure marker, respectively (Acharya et al. 2003; Chang et al. 2002; Dalvitt and Ho 1985; Gong et al. 2006; Lukin and Ho 2004; Viggiano et al. 1979). Table 1 tabulates the $P_{50}$ and $n_{\text {Hill }}$ of $\mathrm{Hb}$ at different $\mathrm{pH}$ values as determined by optical and NMR methods.

Figure 2 shows the visible spectra of $0.025 \mathrm{mM} \mathrm{HbO}_{2}$ in $100 \mathrm{mM}$ Pi buffer pH 7.0 at $25^{\circ} \mathrm{C}$ with IHP (Fig. 2a) and without IHP (Fig. 2b) at $\mathrm{PO}_{2}$ between 2.6 and $155 \mathrm{mmHg}$. Keeping the temperature at $25^{\circ} \mathrm{C}$ ensures protein stability during the course of the experiment. The $\beta$ and $\alpha$ bands at 541 and $577 \mathrm{~nm}$ fall as the $P_{2}$ decreases (Fig. 2a). In contrast, the deoxy $\mathrm{Hb}$ signal at $555 \mathrm{~nm}$ rises. Without $\mathrm{IHP}, \mathrm{Hb}$ shows a sharper change in oxygen saturation 
Table 1 Optical and NMR determined $\mathrm{O}_{2}$-binding parameters for $\mathrm{Hb}$ A

\begin{tabular}{|c|c|c|c|c|}
\hline \multirow[t]{2}{*}{$\mathrm{pH}$} & \multicolumn{2}{|l|}{ IHP } & \multicolumn{2}{|l|}{ No IHP } \\
\hline & $P_{50}(\mathrm{mmHg})$ & $n_{\text {Hill }}$ & $P_{50}(\mathrm{mmHg})$ & $n_{\text {Hill }}$ \\
\hline \multicolumn{5}{|l|}{ Optical } \\
\hline 6.6 & 51.28 & 2.29 & 17.05 & 2.85 \\
\hline 6.8 & 45.43 & 2.18 & 15.73 & 2.93 \\
\hline 7.0 & 40.75 & 2.27 & 13.20 & 2.73 \\
\hline 7.2 & 31.06 & 2.52 & 10.98 & 2.90 \\
\hline 7.3 & 26.44 & 2.73 & & \\
\hline 7.5 & 21.75 & 2.77 & & \\
\hline \multicolumn{5}{|l|}{ NMR } \\
\hline \multicolumn{5}{|l|}{7.0} \\
\hline Val E11 (-2.48 ppm) & 55.72 & 2.02 & 12.94 & 2.62 \\
\hline Tyr C7 (14.0 ppm) & 45.12 & 1.52 & 11.87 & 3.44 \\
\hline
\end{tabular}

(Fig. 2b). Table 2 shows the $P_{50}$ and Hill coefficient of $\mathrm{Hb}$ at different $\mathrm{pH}$ values and with or without the allosteric effector, IHP.

The analysis of the visible spectra yields the $\mathrm{Hb}$ saturation $(Y)$ as a function of $P \mathrm{O}_{2}$. Figure 3 a plots $Y$ against $\mathrm{PO}_{2}$ to produce the $\mathrm{O}_{2}$-binding curves for $\mathrm{Hb}$ in the presence of IHP from $\mathrm{pH} 6.6$ to 7.5. The corresponding $\mathrm{O}_{2}$-binding curves in the absence of IHP show a pronounced left shift, reflecting a higher $\mathrm{O}_{2}$ affinity (Fig. 3b).

Given the $\mathrm{O}_{2}$-binding curve, the analysis based on Eqs. 1 and 2 yields the pH-dependent $P_{50}$ and $n_{\mathrm{Hill}}$ of $\mathrm{Hb}$ with and without IHP over the $\mathrm{pH}$ range from 6.6 to 7.5 (Fig. 4). The values of these $\mathrm{Hb}$ parameters stand in excellent agreement with previous literature reports (Tables 1, 2; Chang et al. 2002; Gong et al. 2006; Lukin and Ho 2004).

Figure 5 shows the ${ }^{1} \mathrm{H}$ NMR spectra of the Tyr $\mathrm{C} 7$ peak at 14.0 and the Val E11 peak at $-2.48 \mathrm{ppm}$ in the presence (left panel) and absence (right panel) of IHP at $\mathrm{PO}_{2}$ values from $2.8 \mathrm{mmHg}$. The proton shared in the $\mathrm{H}$-bond between $\alpha_{1}$ Tyr C7 and $\beta_{2}$ Asp 99 in the T state gives rise to $14 \mathrm{ppm}$ signal and reflects the quaternary structural change at the subunit interface during $\mathrm{R}$ to $\mathrm{T}$ transition (Ho and Russu 1981). As the quaternary state shifts from $T$ to $R$ with increasing $\mathrm{PO}_{2}$, the Tyr $\mathrm{C} 7$ signal intensity decreases. The Val E11 signal of $\mathrm{HbO}_{2}$ at -2.48 serves as a marker of $\mathrm{Hb}$ tertiary structure in the heme pocket. In contrast, its intensity rises as $\mathrm{Hb}$ saturation increases (Acharya et al. 2003; Chang et al. 2002; Dalvitt and Ho 1985; Gong et al. 2006; Lukin and Ho 2004; Viggiano et al. 1979).

Figure 6 overlays the measured $\mathrm{Hb}$ saturation at $\mathrm{pH} 7.4$ and $25^{\circ} \mathrm{C}$, as determined by spectrophotometry and NMR. With and without IHP, the tertiary and quaternary structural markers, as reflected in the Val E11 and Tyr C7 signals, track closely the changes in Hb saturation. Table 3
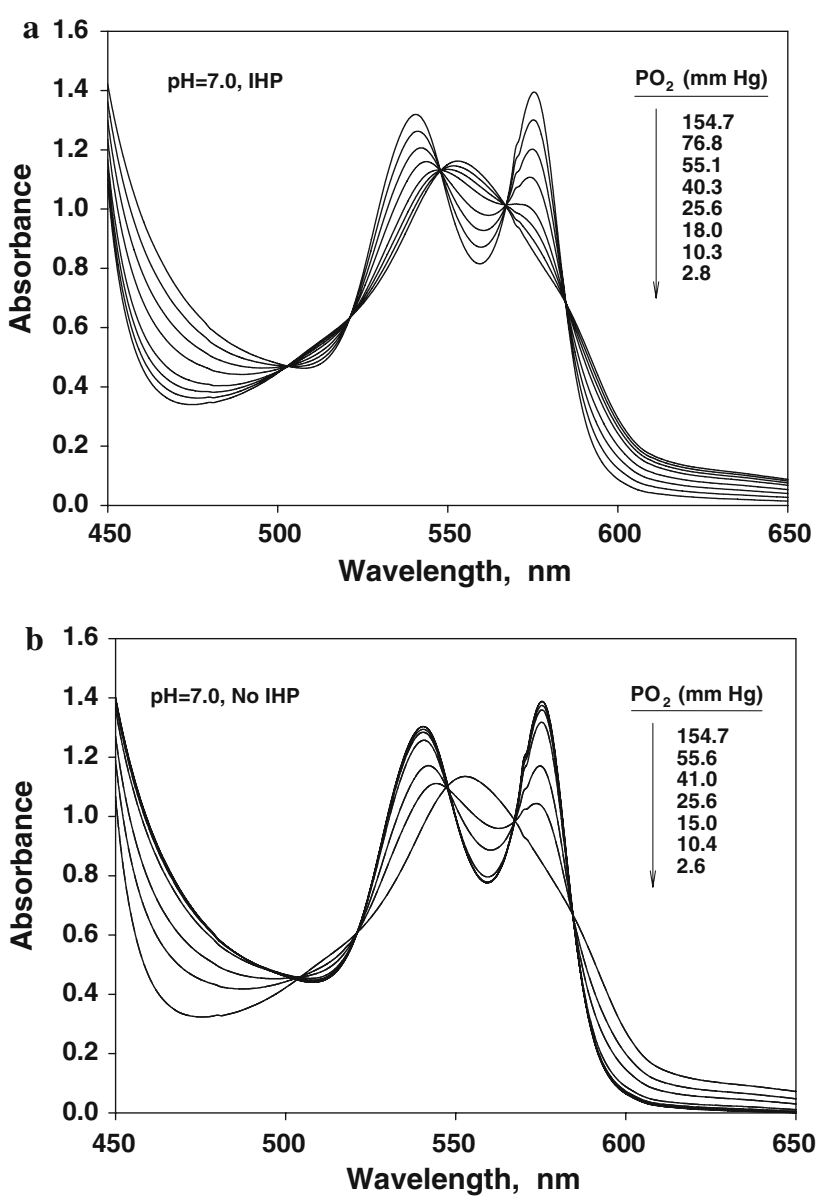

Fig. 2 A representative set of optical spectra of $0.025 \mathrm{mM} \mathrm{HbO}_{2}$ in $100 \mathrm{mM}$ Pi buffer at $\mathrm{pH}=7.0$ at $25^{\circ} \mathrm{C}$ a with IHP b without IHP. The oxygen equilibration system presents a defined $\mathrm{O}_{2}$ mixture to establish different $\mathrm{Hb}$ saturation states. The resultant $\mathrm{Hb}$ spectra show the changes in the $\beta(577 \mathrm{~nm})$ and $\alpha(541 \mathrm{~nm})$ of $\mathrm{HbO}_{2}$, as well as the $555 \mathrm{~nm}$ band of deoxy $\mathrm{Hb}$. Partially oxygenated samples were obtained by equilibrating $\mathrm{Hb}$ in a mixture of $\mathrm{O}_{2}$ and $\mathrm{N}_{2}$, starting from $0,1,2,3,5,7,10$ to $21 \% \mathrm{O}_{2}$, corresponding to $P_{2}$ between 0 and $154 \mathrm{mmHg}$. Each oxygen saturation step requires about $7 \mathrm{~min}$ to reach a steady state. In the IHP experiments, IHP exists in a 5:1 molar ratio of IHP:Hb

summarizes the comparison between the spectrophotometric and NMR results. At each oxygen steady state, $\mathrm{PO}_{2}$, with and without IHP, $\mathrm{HbO}_{2}$ saturation determined by optical $(n=3)$ and by NMR measurements $(n=4-7)$ shows no statistical significant difference $(P>0.05)$.

\section{Discussion}

$\mathrm{Hb}$ oximetry

The closed loop oxygen equilibration system overcomes a major hurdle in studying the structure and function of $\mathrm{Hb}$ by establishing a methodological approach to determine the 
Table 2 Comparative analysis of $\mathrm{O}_{2}$-binding parameters for $\mathrm{Hb} \mathrm{A}$

\begin{tabular}{llllll}
\hline $\begin{array}{l}{[\mathrm{IHP}] /} \\
{[\mathrm{Hb}]}\end{array}$ & $\mathrm{pH}$ & Temp ${ }^{\circ} \mathrm{C}$ & $\begin{array}{l}P_{50} \\
\mathrm{mmHg}\end{array}$ & $n_{\text {Hill }}$ & References \\
\hline 0 & 6.98 & 29 & 14.57 & 2.9 & Lukin and Ho (2004) \\
0 & 7.08 & 29 & 15.90 & 3.2 & Chang et al. (2002) \\
0 & 7.00 & 20 & 8.70 & 2.7 & Asakura and Lau (1978) \\
0 & 7.00 & 20 & 12.02 & 2.9 & Rossi-Fanelli et al. (1961) \\
0 & 7.00 & 25 & 13.20 & 2.7 & This work \\
0 & 7.22 & 29 & 13.90 & 3.2 & Chang et al. (2002) \\
0 & 7.20 & 25 & 10.98 & 2.9 & This work \\
3 & 7.00 & 35 & 40.00 & 2.4 & Gong et al. (2006) \\
50 & 7.00 & 15 & 37.80 & 2.1 & Benesch et al. (1967) \\
5 & 7.00 & 25 & 40.75 & 2.3 & This work \\
50 & 7.40 & 15 & 22.20 & 2.6 & Benesch et al. (1967) \\
5 & 7.50 & 25 & 21.75 & 2.8 & This work \\
\hline
\end{tabular}

$[\mathrm{Hb}]$ is $0.025 \mathrm{mM}$
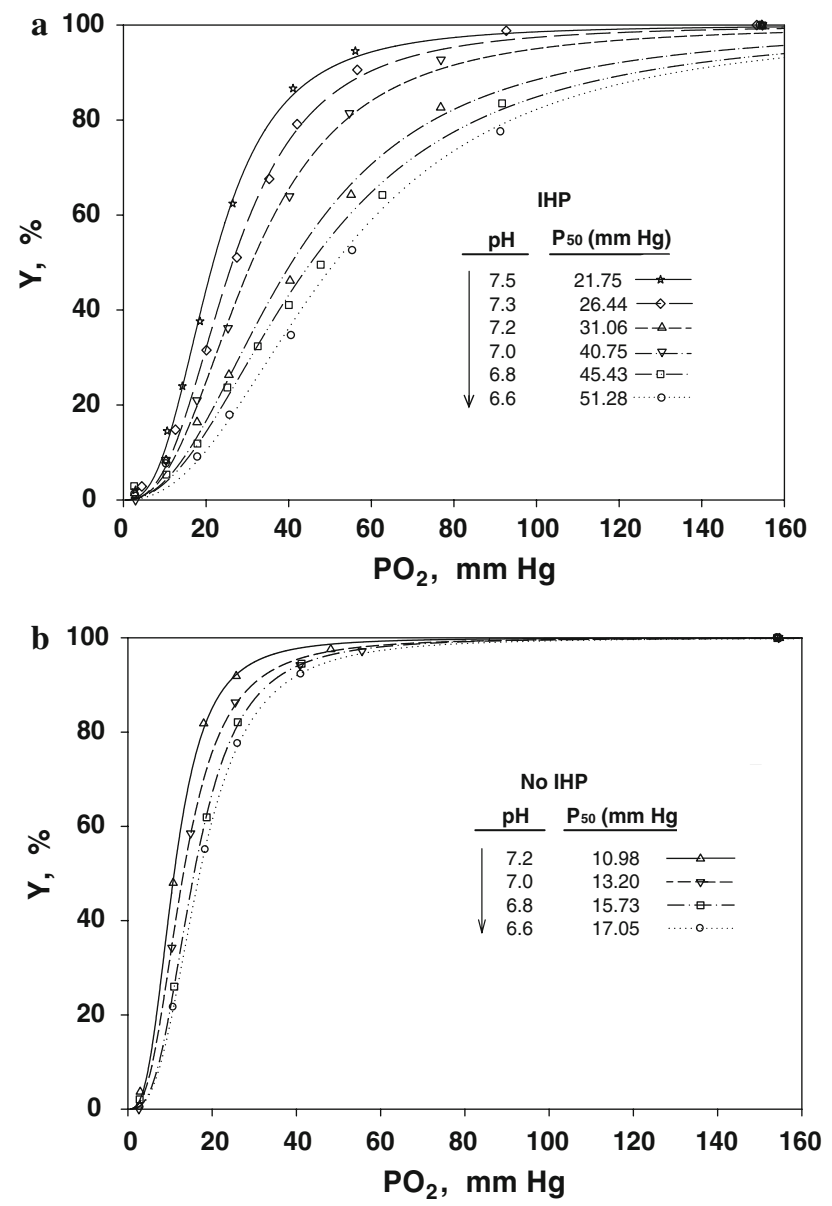

Fig. 3 Oxygen-binding curves of $\mathrm{HbO}_{2}$ at different $\mathrm{pH}$ values in $100 \mathrm{mM}$ Pi buffer at $25^{\circ} \mathrm{C}$ a with IHP b without IHP. IHP right shifts the $P_{50}$ at $\mathrm{pH} 7.0$ from 13.20 to $40.75 . Y$ is percentage of $\mathrm{HbO}_{2}$. Error bars representing standard deviation are too small to detect in the figure
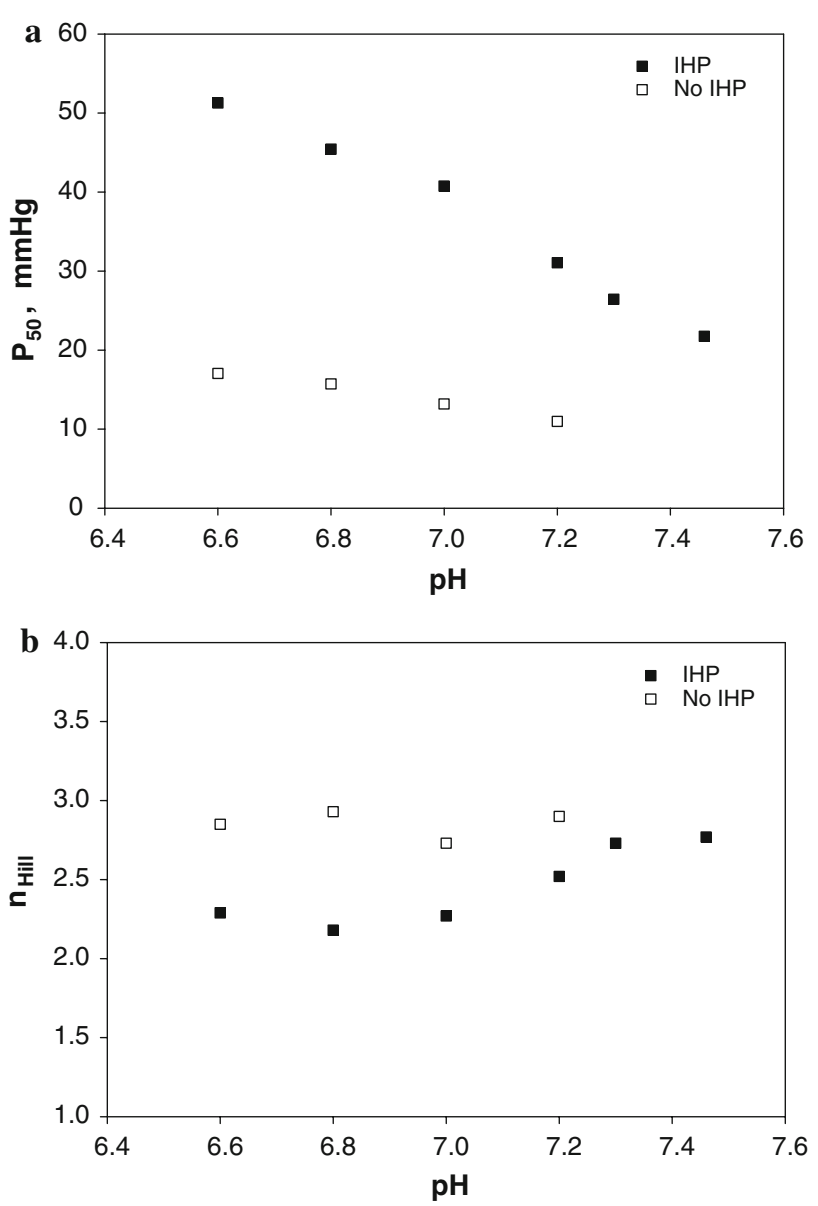

Fig. 4 Plot of $P_{50}$ and $n_{\mathrm{Hill}}$ of $\mathrm{Hb} \mathrm{A}$ as a function of $\mathrm{pH}$ at $25^{\circ} \mathrm{C}$ with IHP and without IHP. a In the presence of IHP, $P_{50}$ decreases from 51.28 to 21.75 as $\mathrm{pH}$ increases from 6.6 to 7.5 . Without IHP, $P_{50}$ decreases only from 17.05 to 10.98 , as $\mathrm{pH}$ increases from 6.6 to 7.2. b $\mathrm{HbO}_{2}$ with IHP shows $n_{\mathrm{Hill}}$ increasing from 2.29 to 2.77 as $\mathrm{pH}$ increases from 6.6 to 7.5 . Without IHP, the $n_{\text {Hill }}$ changes from 2.85 to 2.90 as $\mathrm{pH}$ rises from 6.6 to 7.2

spectral characteristics, given a defined $\mathrm{Hb}$ saturation at a specified $\mathrm{PO}_{2}, \mathrm{pH}$, allosteric modulation and temperature for both spectrophotometric and NMR experiments. The system avoids the experimental uncertainty of defining $\mathrm{Hb}$ saturation by mixing $\mathrm{HbO}_{2}$ with deoxy $\mathrm{Hb}$ (Fetler et al. 1995; Viggiano and Ho 1979). Such a mixing protocol does not always define the state of $\mathrm{Hb}$ saturation, because it assumes that the $\mathrm{Hb}$ saturation will reflect the fractional amount of $\mathrm{HbO}_{2}$ in the mixture. It does not account for the contribution from any dissolved $\mathrm{O}_{2}$ in the solution or from the action of any residual dithionite used to remove excess $\mathrm{O}_{2}$ in the deoxy $\mathrm{Hb}$ solution.

With the oxygen equilibration system, the spectrophotometric assay shows that the $\beta(541 \mathrm{~nm})$ and $\alpha(577 \mathrm{~nm})$ bands of $\mathrm{HbO}_{2}$ decline with decreasing $\mathrm{PO}_{2}$. Conversely, the deoxy $\mathrm{Hb}$ signal at $555 \mathrm{~nm}$ increases. At present, the oximeter system can reach a $\mathrm{PO}_{2}$ of about $3 \mathrm{mmHg}$. No 


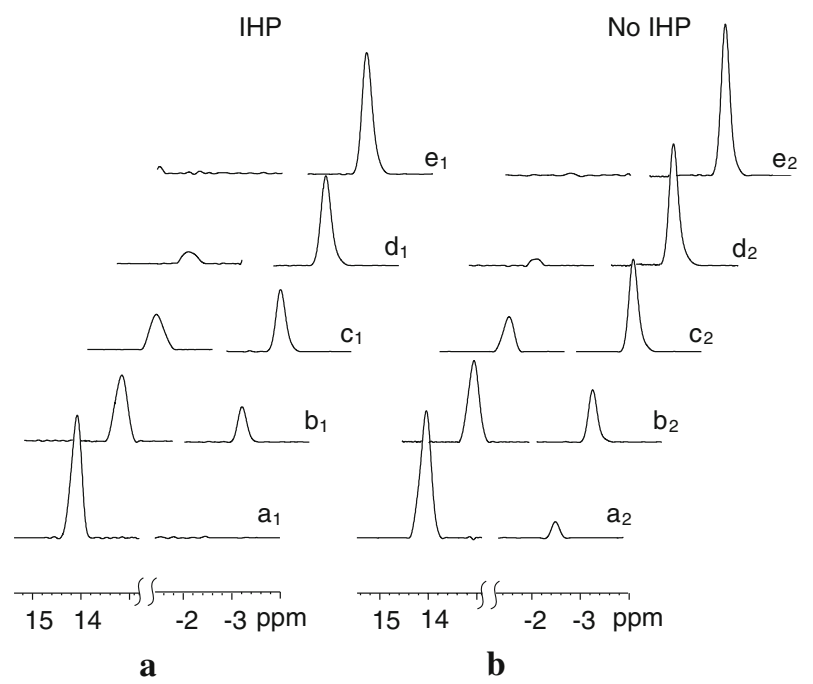

Fig. $5{ }^{1} \mathrm{H}$ NMR spectra of Val E11 and Tyr C7 as a function of $\mathrm{Hb}$ oxygenation a with IHP b without IHP. As $P_{2}$ increases, the Tyr C7 signal at $14.0 \mathrm{ppm}$ falls, while the Val E11 signal at $-2.48 \mathrm{ppm}$ rises. The spectra show $\mathrm{HbO}_{2}$ at $0,12.5,25,50,75$ and $100 \%$ oxygenation

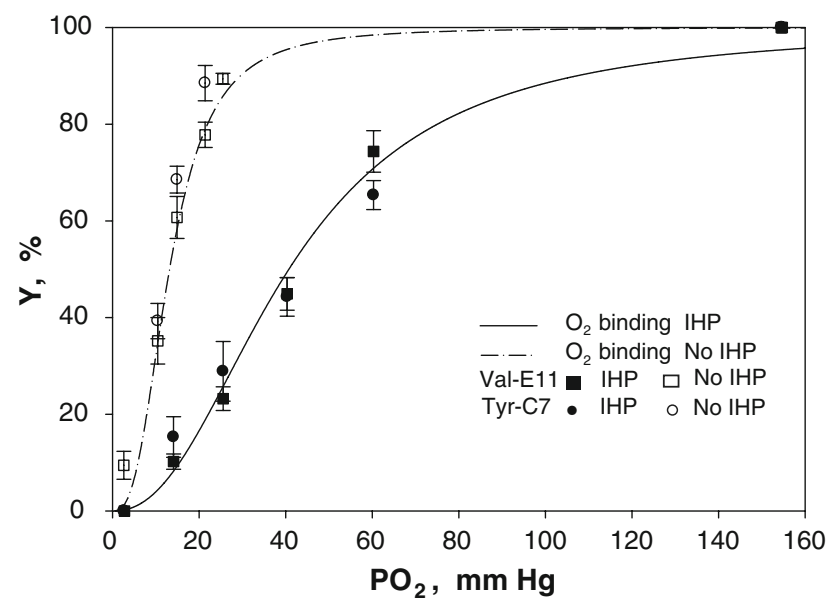

Fig. 6 Plot of $\mathrm{Hb}$ saturation versus $\mathrm{PO}_{2}$ as determined by spectrophotometry and by the NMR signals of Val E11 and Tyr C7. The solid and dashed lines show the oxygen-binding curves of $\mathrm{HbO}_{2}$ with and without IHP. Overlaying these lines are the corresponding changes in the NMR signals of the Val E11 (filled square) and the Tyr C7 (filled circle) of $\mathrm{Hb}$ in the presence of IHP, and the Val E11 (open square) and the Tyr C7 (open circle) signals of $\mathrm{Hb}$ in the absence of IHP. Error bars represent standard deviation

significant $\mathrm{Hb}$ degradation to metHb appears during the course of the spectrophotometry experiments. The plot of $\mathrm{Hb}$ saturation as a function of $\mathrm{PO}_{2}$ yields the familiar oxygen-binding curves:

At $25^{\circ} \mathrm{C}$ and without IHP, $\mathrm{Hb}$ at $\mathrm{pH} 7.2$ exhibits a $P_{50}$ of $10.98 \mathrm{mmHg}$ and a $n_{\mathrm{Hill}}$ of 2.90 . With IHP and $\mathrm{Hb}$ at a ratio of 5:1, the $\mathrm{O}_{2}$-binding curve right shifts as the $\mathrm{Hb}$ decreases its $\mathrm{O}_{2}$ affinity. $\mathrm{Hb} P_{50}$ increases to $31.06 \mathrm{mmHg}$, while $n_{\text {Hill }}$ decreases to 2.52 . As $\mathrm{pH}$ decreases from $\mathrm{pH} 7.2$ to 6.6 in the absence of IHP, the $P_{50}$ also increases from
Table $3 \mathrm{HbO}_{2}$ saturation determined by spectrophotometry and NMR

\begin{tabular}{lrllll}
\hline $\begin{array}{l}\mathrm{PO}_{2} \\
(\mathrm{mmHg})\end{array}$ & \multicolumn{1}{l}{$\begin{array}{l}Y_{\text {Optical }} \\
(\%)\end{array}$} & $\begin{array}{l}Y_{\text {Tyr-C7 }} \\
(\%)\end{array}$ & $\begin{array}{l}\Delta_{1} \\
(\%)\end{array}$ & $\begin{array}{l}Y_{\text {Val-E11 }} \\
(\%)\end{array}$ & $\begin{array}{l}\Delta_{2} \\
(\%)\end{array}$ \\
\hline With IHP & & & & & \\
2.8 & $1.4 \pm 1.0$ & 0.0 & 1.4 & 0.0 & 1.4 \\
14.1 & $12.2 \pm 3.7$ & $15.3 \pm 3.9$ & 3.1 & $10.2 \pm 1.9$ & 2.0 \\
25.6 & $26.3 \pm 5.1$ & $28.9 \pm 5.7$ & 2.6 & $23.2 \pm 3.0$ & 3.1 \\
40.3 & $46.2 \pm 3.7$ & $44.3 \pm 2.0$ & 1.9 & $44.9 \pm 4.1$ & 1.3 \\
60.3 & $68.7 \pm 1.9$ & $65.3 \pm 2.7$ & 3.4 & $74.3 \pm 6.3$ & 5.6 \\
154.5 & $100.0 \pm 0.8$ & 100.0 & 0.0 & 100.0 & 0.0 \\
Without IHP & & & & & \\
2.6 & $2.7 \pm 1.5$ & 100.0 & 2.7 & $9.4 \pm 2.9$ & 6.7 \\
10.4 & $34.3 \pm 1.1$ & $39.3 \pm 3.6$ & 5 & $35.0 \pm 4.8$ & 0.7 \\
14.9 & $58.5 \pm 4.6$ & $68.5 \pm 2.8$ & 10 & $60.7 \pm 4.3$ & 2.2 \\
21.4 & $79.0 \pm 5.4$ & $88.5 \pm 3.6$ & 9.5 & $77.8 \pm 2.6$ & 1.2 \\
25.5 & $86.3 \pm 4.9$ & $\mathrm{ND}$ & $\mathrm{ND}$ & $89.4 \pm 1.1$ & 3.1 \\
154.7 & $100.0 \pm 0.2$ & 100.0 & 0.0 & 100.0 & 0 \\
\hline
\end{tabular}

$N D$ not detectable; $Y=\frac{\mathrm{HbO}_{2}}{\mathrm{HbO}_{2}+\mathrm{Hb}}(\mathrm{Hb}$ saturation $) . \quad Y_{\text {Optical }}=\mathrm{Hb}$ saturation determined by spectrophotometric measurement. $Y_{\mathrm{Tyr}-}$ $\mathrm{C} 7=100 \%-$ signal intensity of Tyr C7 $=$ Hb saturation determined by NMR measurement of the Tyr C7 signal. $Y_{\text {Val-E11 }}=\mathrm{Hb}$ saturation determined by spectrophotometric measurement of the Val E11 signal, $\Delta_{1}=\left(Y_{\text {Optical }}-Y_{\text {Tyr-C7 }}\right) ; \Delta_{2}=\left(Y_{\text {Optical }}-Y_{\text {Val-E11 }}\right) ; P_{2}=$ $\left(P_{\text {Barometer }}-P_{\mathrm{H}_{2} \mathrm{O}}\right) \times 0.209$. With IHP, optical experiment $(n=3)$; NMR experiment $(n=7)$. Without IHP, optical experiment $(n=3)$; NMR experiment $(n=4)$. Errors are expressed as standard deviation

10.98 to 17.05 , consistent with the acid-Bohr effect. The Hill coefficient, however, shows no change. In the presence of IHP and $\mathrm{pH} 6.6$, the $P_{50}$ increases from 31.06 to 51.28 and $n_{\text {Hill }}$ decreases from 2.52 to 2.29 .

These $\mathrm{Hb}$ oxygen-binding curves agree with previous literature reports and validate the oxygen equilibration system's capacity to establish accurately the Hb saturation (Table 2; Ogata 2000; Vorger and Matelin 1985; Yonetani et al. 2002; Imai 1981). They also confirm the effectiveness of IHP, a stable analog of the endogenous allosteric effector BPG (2,3 bisphophoglycerate) in erythrocyte, to modulate the $\mathrm{HbO}_{2}$-binding affinity and cooperativity. Without IHP or BPG, $\mathrm{Hb}$ exhibits a high $\mathrm{O}_{2}$ affinity. $\mathrm{Hb}$ has a decreased efficiency in unloading $\mathrm{O}_{2}$. With the allosteric effector IHP or BPG, $\mathrm{Hb}$ decreases its $\mathrm{O}_{2}$ affinity. The $\mathrm{O}_{2}$-binding curve shifts to the right (Levitzki 1978). Indeed, erythrocytes increase BPG level during physiological adaptation to high altitude in order to improve $\mathrm{O}_{2}$ unloading in the capillary (Weber 2007).

Val E11 signal as a vascular $P_{2}$ biomarker

The $\gamma \mathrm{CH}_{3} \mathrm{Val} \mathrm{E} 11$ signal of $\mathrm{Mb}$ has presented an approach to measure the intracellular $\mathrm{PO}_{2}$ in isolated myocardium 
(Kreutzer et al. 1992). Since NMR studies have already observed the proximal histidyl $\mathrm{N}_{\delta} \mathrm{H}$ signals from erythrocyte, they implied the availability of the Val E11 and Tyr C7 signals as vascular $\mathrm{PO}_{2}$ biomarkers in vivo (Kreutzer et al. 1993; Tran et al. 1999). Detecting the $\gamma \mathrm{CH}_{3}$ signal of Val E11 would immediately improve the detection sensitivity given the three-proton intensity of the $\mathrm{CH}_{3}$ group versus one-proton intensity of the proximal histidyl $\mathrm{N}_{\delta} \mathrm{H}$. Moreover, it would overcome the requirement to secure a normalizing signal under anoxia, since the Val E11 signal reaches its maximal intensity under oxygenated conditions. However, its function as an oximeter must overcome the criticism that the Val E11 signal might not correspond to $\mathrm{Hb}$ saturation, since it does not have a direct role in propagating the quaternary structural perturbation as defined in the Perutz's interpretation of the Monod, Changeux and Wyman (MWC) two-state model of $\mathrm{Hb}$ oxygen binding (Fetler et al. 1995; Monod et al. 1965; Weissbluth 1974; Perutz 1989; Perutz et al. 1998; Bruno et al. 2001).

The present study shows that the Val E11 signal does track closely $\mathrm{Hb}$ saturation in the presence and absence of IHP and at different $\mathrm{pH}$ values. As $\mathrm{Hb}$ saturation increases or decreases, so also does the Val E11 signal intensity. Even though the Perutz model localizes the cooperativity energy in a specific set of quaternary structural changes, it does not dismiss the presence of tertiary structural changes during the $\mathrm{R}$ to $\mathrm{T}$ transition (Perutz et al. 1968; Muirhead et al. 1967). Such tertiary structural change can still reflect the $\mathrm{Hb}$ oxygenation state.

\section{Tyr C7 signal as a vascular $P \mathrm{O}_{2}$ biomarker}

The correlation between the tertiary and quaternary structural changes becomes apparent in the comparative analysis of the Val E11 and Tyr C7 signals. From the NMR spectra, the Val E11 signal shows an inverse relation with the Tyr C7 signal, which originates from a $\mathrm{T}$ state sensitive hydrogen bond at the subunit interface. As $\mathrm{Hb}$ switches from the $\mathrm{R}$ to $\mathrm{T}$ state, the Perutz model specifies a hydrogen bond formation step (Ho and Russu 1981; Mihailescu and Russu 2001). In essence, the Tyr C7 peak at $14 \mathrm{ppm}$ originating from a hydrogen bond at the $\alpha_{1} \beta_{2}$ subunit interface reports directly on the quaternary structure of $\mathrm{Hb}$ (Mihailescu and Russu 2001). This unique $\mathrm{Hb}$ signal provides an alternative to the proximal histidyl $\mathrm{N}_{\delta} \mathrm{H}$ signal of deoxy $\mathrm{Mb}$ to assess the deoxygenated state. As $\mathrm{Hb}$ desaturates and undergoes the $\mathrm{R}$ to $\mathrm{T}$ transition, the Tyr C7 signal increases correspondingly.

Both the Val E11 and Tyr C7 signals track closely the Hb saturation and imply that tertiary structural perturbation of $\mathrm{Hb}$, even though unlinked with the direct control of $\mathrm{O}_{2}$ affinity in the Perutz model, can still reflect the $\mathrm{Hb}$ saturation state. The observed correlation of both the Val E11 and Tyr $\mathrm{C} 7$ signals with the $\mathrm{Hb}$ saturation raises a question about imputing a specific localized structural change to explain fully the energetics of cooperativity (Shulman et al. 1975; Eaton et al. 1999).

Implications for in vivo vascular $\mathrm{PO}_{2}$ measurements

Assessing the vascular $P_{2}$ gradient in vivo poses many technical challenges. Yet, that measurement provides critical insight into the metabolic regulation in tissue. In the physiology field, many investigators have relied mainly on near infrared spectroscopy (NIRS) methods to assess the vascular $\mathrm{PO}_{2}$ with the NIRS signal of $\mathrm{Hb}$. Both oxygenated and deoxygenated $\mathrm{Hb}$ have absorbances at 760 and $850 \mathrm{~nm}$. However, the deoxy $\mathrm{Hb}$ has a sharper and more intense absorbance than oxy $\mathrm{Hb}$ at $760 \mathrm{~nm}$. The 760 and $850 \mathrm{~nm}$ absorption bands form then a basis to assess the overall tissue $\mathrm{PO}_{2}$ (Jobsis 1977). Any blood volume change would affect both the oxy- and deoxy-Hb signals. By arguing that the NIRS signals originate predominantly from $\mathrm{Hb}$, researchers have then presumed an exclusive measurement of the vascular $\mathrm{PO}_{2}$ (Seiyama et al. 1988; Wilson et al. 1989; Seiyama et al. 1988). Unfortunately, $\mathrm{Mb}$ exhibits identical spectral features. Others have presented evidence to show that the NIRS signal contains a major $\mathrm{Mb}$ contribution (Hoofd et al. 2009; Nioka et al. 2009; Tran et al. 1999; Ponganis et al. 2008).

The ${ }^{1} \mathrm{H}$ NMR approach does not encounter the issue of overlapping spectra, for it can discriminate the $\mathrm{Mb}$ and $\mathrm{Hb}$ signals of the Val E11 and the proximal histidyl $\mathrm{N}_{\delta} \mathrm{H}$ (Kreutzer and Jue 1991; Kreutzer et al. 1992, 1993). Moreover, the Tyr C7 signal only appears in Hb. Even though some researchers have asserted that erythrocyte $\mathrm{Hb}$ signals do exhibit an NMR visible signal, many studies have presented experimental evidence countering such a viewpoint (Fetler et al. 1995; Ho and Russu 1981; Lindstrom and Koenig 1974; Wang et al. 1997). In fact, recent NMR experiments have detected the proximal histidyl $\mathrm{N}_{\delta} \mathrm{H}$ signal of deoxy $\mathrm{Hb}$ in human and seal skeletal muscle (Tran et al. 1999; Ponganis et al. 2008).

However, the algorithm to convert the $\mathrm{Hb}$ signals into vascular $\mathrm{PO}_{2}$ differs from the process to obtain the intracellular $\mathrm{PO}_{2}$ with the $\mathrm{Mb}$ signal. In the cell, the $\mathrm{Mb}$ content does not change. The proximal histidyl $\mathrm{N}_{\delta} \mathrm{H}$ or Val E11 peak intensity correlates directly with changes in the cellular $\mathrm{PO}_{2}$. Blood volume, however, does not remain constant and can alter the signal intensity. Both blood volume and vascular oxygenation then can alter the signal intensity of $\mathrm{Hb}$. Relying only on the normalized signal intensity of the deoxy $\mathrm{Hb}$ histidyl $\mathrm{N}_{\delta} \mathrm{H}$ or Val E11 will lead to an erroneous determination. Blood volume change, however, affects both the Val E11 and the proximal histidyl $\mathrm{N}_{\delta} \mathrm{H}$ signal. As a consequence, using the signal intensity ratio of Val E11 and proximal 
histidyl $\mathrm{N}_{\delta} \mathrm{H}$ would overcome confounding contribution from blood volume and lead to the correct determination of the vascular $\mathrm{PO}_{2}$ (Kreutzer et al. 1992).

Even though the present study has established the feasibility of using the Val E11 or Tyr C7 signal as a biomarker of the $\mathrm{Hb}$ oxygenation state, the implementation of a routine NMR method to determine vascular $\mathrm{PO}_{2}$ in vivo still requires additional technical advances. These advances must address the interfering background signal arising from lipids and other endogenous molecules in the ${ }^{1} \mathrm{H}$ NMR spectra from typical $1.5 \mathrm{~T}$ scanners. Moreover, they must also provide some discrimination of the compartmentalized vascular $\mathrm{PO}_{2}$ in arteries, veins and capillaries. Several studies have already begun to show some promising spectroscopic approaches (Lin et al. 2007). Nevertheless, the study has established that the Val E11 and Tyr C7 signals can report accurately the state of $\mathrm{Hb}$ oxygenation and will lead to new insights into the regulation of oxygen transport in tissue.

\section{Conclusion}

This study details an oxygen equilibration system that permits a comparative spectrophotometric and NMR determination of $\mathrm{Hb}$ saturation and which helps to address the utility of the Val E11 and the Tyr C7 as biomarkers of vascular $\mathrm{PO}_{2}$. Under different $\mathrm{PO}_{2}, \mathrm{pH}$ values and with or without IHP, the spectrophotometric assay of $\mathrm{Hb}$ saturation agrees with the NMR determination using the Val E11 and Tyr C7 signals. The oxygen-binding curves stand in excellent agreement with literature. Consequently, the results verify the validity of using either the Val E11 or Tyr $\mathrm{C} 7$ signals to assess $\mathrm{Hb}$ saturation and open a new direction to study vascular $\mathrm{PO}_{2}$, oxygen transport and $\mathrm{Hb}$ structurefunction.

Acknowledgments We gratefully acknowledge the funding support from NIH GM 58688 (TJ) and the invaluable scientific discussion with Drs. Ping-Chang Lin and Renuka Sriram.

Open Access This article is distributed under the terms of the Creative Commons Attribution Noncommercial License which permits any noncommercial use, distribution, and reproduction in any medium, provided the original author(s) and source are credited.

\section{References}

Acharya SA, Malavalli A, Peterson E, Ho C, Manjula BN, Friedman JM (2003) Probing the conformation of hemoglobin presbyterian in the R-state. J Protein Chem 22:221-230

Antonini E, Brunori M (1971) Hemoglobin and myoglobin in their reactions with ligands. Elsevier, Amsterdam
Asakura T, Lau P (1978) Sequence of oxygen binding by hemoglobin. Proc Natl Acad Sci USA 75:5462-5465

Benesch R, Benesch RE, Yu CI (1967) Reciprocal binding of oxygen and diphosphoglycerate by human hemoglobin. Biochemistry 59:526-532

Bruno S, Bonaccio M, Bettati S, Rivetti C, Viappiani C, Abbruzzetti S, Mozzarelli A (2001) High and low oxygen affinity conformations of T state hemoglobin. Protein Sci 10:2401-2407

Chang CK, Simplaceanu V, Ho C (2002) Effects of amino acid substitutions at beta 131 on the structure and properties of hemoglobin: evidence for communication between alpha 1 beta 1 - and alpha 1 beta 2 -subunit interfaces. Biochemistry 41:5655

Chung Y, Mole PA, Sailasuta N, Tran TK, Hurd R, Jue T (2005) Control of respiration and bioenergetics during muscle contraction. Am J Physiol Cell Physiol 288:C730-C738

Dalvitt C, Ho C (1985) Proton nuclear overhauser effect investigation of the heme pockets in ligated forms hemoglobin conformational differences between oxy and carbonmonoxy form. Biochemistry 24:3398-3407

Eaton WA, Henry ER, Hofrichter J, Mozzarelli A (1999) Is cooperativity oxygen binding by hemoglobin really understood? Nature Struct Biol 6:351-358

Fetler BK, Simplaceanu V, Ho C (1995) ${ }^{1} \mathrm{H}$ NMR investigation of the oxygenation of hemoglobin in intact human red blood cells. Biophys J 68:681-693

Gong Q, Simplaceanu V, Lukin JA, Giovannelli JL, Ho NT, Ho C (2006) Quaternary structure of carbonmonoxyhemoglobins in solution: structural changes induced by the allosteric effector inositol hexaphosphate. Biochemistry 45:5140-5148

Ho C, Russu I (1981), Proton nuclear magnetic resonance investigation of hemoglobins. Methods in Enzymology, Academic, New York

Hoofd L, Colier W, Oeseburg B (2009) A modeling investigation to the possible role of myoglobin in human muscle in near infrared spectroscopy (NIRS) measurements. Adv Exp Med Biol 530:637-643

Hore PJ (1983) A new method for water suppression in the proton NMR spectra of aqueous solutions. J Magn Reson 54:539-542

Imai K (1981) Measurement of accurate oxygen equilibrium curves by an automatic oxygenation apparatus. Methods Enzymol 76:438-449

Jobsis FF (1977) Noninvasive, infrared monitoring of cerebral and myocardial oxygen sufficiency and circulatory parameters. Science 198:1264-1267

Jue T (1994) Measuring tissue oxygenation with the ${ }^{1} \mathrm{H}$ NMR signals of myoglobin. In: Gillies RJ (ed) NMR in physiology and biomedicine. Academic Press, New York

Kreutzer U, Jue T (1991) ${ }^{1} \mathrm{H}$ nuclear magnetic resonance deoxymyoglobin signal as indicator of intracellular oxygenation in myocardium. Am J Physiol 30:H2091-H2097

Kreutzer U, Wang DS, Jue T (1992) Observing the ${ }^{1} \mathrm{H}$ NMR signal of the myoglobin Val-E11 in myocardium: an index of cellular oxygenation. Proc Natl Acad Sci USA 89:4731-4733

Kreutzer U, Chung Y, Butler D, Jue T (1993) ${ }^{1} \mathrm{H}-\mathrm{NMR}$ characterization of the human myocardium myoglobin and erythrocyte hemoglobin signals. Biochim Biophys Acta 1161:33-37

Levitzki A (1978) Quantitative aspects of allosteric mechanism. Springer, Berlin

Lin PC, Kreutzer U, Jue T (2007) Anisotropy and temperature dependence of myoglobin translational diffusion in myocardium: implication on oxygen transport and cellular architecture. Biophys J 92:2608-2620

Lindstrom TR, Koenig SH (1974) Magnetic field-dependent water proton spin lattice relaxation rates of hemoglobin solutions and whole blood. J Magn Reson 15:344-353 
Lukin JA, Ho C (2004) The structure-function relationship of hemoglobin in solution at atomic resolution. Chem Rev 104:1219-1230

Mihailescu MR, Russu IM (2001) A signature of the T $\rightarrow$ R transition in human hemoglobin. Proc Natl Acad Sci USA 98:3773-3777

Monod J, Wyman J, Changeux JP (1965) On the nature of allosteric transitions: a plausible model. J Mol Biol 8:8-118

Muirhead H, Cox JM, Mazzarella L, Perutz MF (1967) Structure and function of haemoglobin. 3. A three-dimensional Fourier synthesis of human deoxyhaemoglobin at 5.5 Angstrom resolution. J Mol Biol 28:117-156

Nioka S, Wang DJ, Im J, Hamaoka T, Wang ZJ, Leigh JS, Chance B (2009) Simulation of $\mathrm{Mb} / \mathrm{Hb}$ in NIRS and oxygen gradient in the human and canine skeletal muscle using H-NMR and NIRS. Adv Exp Med Biol 578:223-228

Ogata Y (2000) Characteristics and function of human hemoglobin vesicles as an oxygen carrier. Polym Adv Technol 11:205-209

Perutz MF (1989) Mechanisms of cooperativity and allosteric regulation in proteins. Q Rev Biophys 22:139-236

Perutz MF, Muirhead H, Cox JM, Goaman LC (1968) Threedimensional Fourier synthesis of horse oxyhaemoglobin at $2.8 \mathrm{~A}$ resolution: the atomic model. Nature 219:131-139

Perutz MF, Wilkinson AJ, Paoli M, Dodson GG (1998) The stereochemical mechanism of the cooperative effects in hemoglobin revisited. Annu Rev Biophys Biomol Struct 27:1-34

Ponganis PJ, Kreutzer U, Stockard TK, Lin PC, Sailasuta N, Tran TK, Hurd R, Jue T (2008) Blood flow and metabolic regulation in seal muscle during apnea. J Exp Biol 211:3323-3332

Rossi-Fanelli A, Antonini E, Caputo A (1961) Studies on the relations between molecular and functional properties of hemoglobin. II. The effect of salts on the oxygen equilibrium of human hemoglobin. J Biol Chem 236:397-400

Seiyama A, Hazeki O, Tamura M (1988) Noninvasive quantitative analysis of blood oxygenation in the rat skeletal muscle. J Biochem 103:419-424
Shulman R, Hopfield JJ, Ogawa S (1975) Allosteric interpretation of hemoglobin properties. Q Rev Biophys 8:325-420

Tran TK, Sailasuta N, Kreutzer U, Hurd R, Chung Y, Mole P, Kuno S, Jue T (1999) Comparative analysis of NMR and NIRS measurements of intracellular $\mathrm{PO}_{2}$ in human skeletal muscle. Am J Physiol 276:R1682-R1690

Viggiano G, Ho C (1979) Proton nuclear magnetic resonance investigation of structural changes associated with cooperative oxygenation of human adult hemoglobin. Proc Natl Acad Sci USA 76:3673-3677

Viggiano G, Ho NT, Ho C (1979) Proton nuclear magnetic resonance and biochemical studies of oxygenation of human hemoglobin in deuterium oxide. Biochemistry 18:5238-5247

Vorger P, Matelin D (1985) A low cost apparatus for the automatic determination of precise oxygen equilibrium curves on red blood cell suspensions. Comp Biochem Physiol 82:355-359

Wang D, Kreutzer U, Chung Y, Jue T (1997) Myoglobin and hemoglobin rotational diffusion in the cell. Biophys J 73:27642770

Weber RE (2007) High-altitude adaptations in vertebrate hemoglobins. Respir Physiol Neurobiol 158:132-142

Weissbluth M (1974) Cooperativity and electronic properties. Mol Biol Biochem Biophys 15:1-175

Wilson JR, Mancini DM, McCully K, Feraro N, Lanoce V, Chance B (1989) Noninvasive detection of skeletal muscle underperfusion with near-infrared spectroscopy in patients with heart failure. Circulation 80:1668-1674

Yonetani T, Park SI, Tsuneshige A, Imai K, Kanaori K (2002) Global allostery model of hemoglobin. Modulation of $\mathrm{O}(2)$ affinity, cooperativity, and Bohr effect by heterotrophic allosteric effectors. J Biol Chem 277:34508-34520 